Editorial

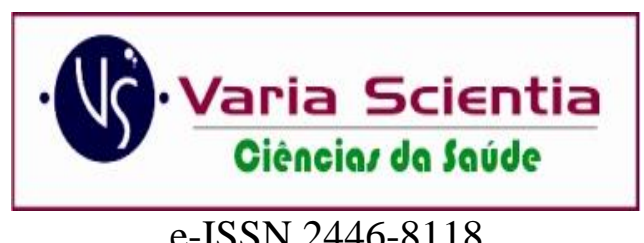

e-ISSN 2446-8118

\title{
EDUCAÇÃO PERMANENTE E SISTEMA ÚNICO DE SAÚDE
}

\author{
Rosa Maria Rodrigues ${ }^{1}$ \\ Ana Cristina de Moraes $^{2}$ \\ Gilson Fernandes da Silva ${ }^{3}$
}

A criação do Sistema Único de Saúde (SUS), impôs a necessidade de formação dos profissionais de saúde para a atuação no sistema desde as graduações em saúde, mas mais incisivamente a formação dos trabalhadores que estavam nos serviços de saúde e dos que a ele se incorporavam, uma vez que sua implantação reformulou o modo de produzir a saúde dos brasileiros.

Em virtude disso, iniciativas governamentais desencadearam ações de educação permanente, desde início dos anos de 1990, após a regulamentação do SUS, cujos primeiros movimentos constituíram a oferta de cursos de especialização em saúde da família, em articulação com instituições de ensino do país e cursos para formação dos trabalhadores para o desenvolvimento do Programa Saúde da Família, que depois foi reconhecido como Estratégia de Saúde da Família, principal movimento para mudança do modelo assistencial e para o fortalecimento da Atenção Primária em Saúde; posteriormente, a partir do diagnóstico de que o processo de formação não atendia o quanto se esperava para preparar os trabalhadores, foi lançada, em 2004 a Política Nacional de Educação Permanente em saúde (PNEPS), reformulada em 2007 e que está em vigência.

O movimento pela Educação Permanente em Saúde (EPS) foi se construindo para mudar sua forma de realização, especialmente se contrapondo à Educação Continuada reconhecida como insuficiente, pois entendia-se que focalizava exclusivamente em processos formais de formação, estabelecidos verticalmente e, portanto, deslocados dos processos cotidianos do trabalho em saúde. Advogava-se que em seu lugar fossem realizadas exclusivamente as ações condizentes com a EPS, a partir do cotidiano e para solução dos problemas vivenciados no trabalho.

A educação permanente prevê que os processos formativos estejam entrelaçados ao processo de trabalho, em que os problemas e/ou dificuldades emergidos na prática diária dos serviços de saúde oportunizassem momentos de qualificação no próprio ambiente e horário de trabalho, com o objetivo de estimular o interesse do trabalhador a busca por novos conhecimentos.

A política previa orientações metodológicas específicas, portanto, assim como financiamento diferenciado e nova forma de gestão das iniciativas para formação na direção do SUS. Passados os anos, e com as dificuldades orçamentárias do governo federal, o impulso inicial foi se tornando menos fortalecido e, em 2017 e 2018 discutia-se sua revitalização, de forma que não perdesse o esforço de quase duas décadas de trabalho e de criação de espaços de gestão da formação dos trabalhadores para o SUS, como a Secretaria de Gestão do Trabalho e da Educação em Saúde (SGTES) e de seu Departamento de Gestão da Educação na Saúde (DEGES) criados em 2003 para alavancar a formação no Ministério da Saúde (MS), mas reconhecia-se que os cenários eram adversos valendo o esforço para retomar sua vivacidade ${ }^{1}$.

\footnotetext{
${ }^{1}$ Enfermeira. Doutora em Educação. Professora no Programa de Pós-graduação em Biociências e Saúde da Universidade Estadual do Oeste do Paraná - Unioeste, Campus Cascavel/PR. Editora da Revista Varia Scientia-Ciências da Saúde.

${ }^{2}$ Enfermeira. Mestranda no Programa de Pós-graduação em Biociências e Saúde da Universidade Estadual do Oeste do Paraná - Unioeste, Campus Cascavel/PR.

${ }^{3}$ Enfermeiro. Mestre em Biociências e Saúde. Coordenador e Tutor do Programa de Residência Multiprofissional em Saúde da Família, Escola de Saúde Pública Municipal, Secretaria Municipal de Saúde Cascavel/PR.
} 
Ao par disso, outras iniciativas caminhavam como a criação da Universidade Aberta do Sistema Único de Saúde (Unasus) para oferta, pelas universidades públicas, de cursos no modelo de Educação à Distância (EAD), na esteira da criação da Universidade Aberta do Brasil (UAB). A Unasus tem disponibilizado cursos, materiais didáticos e audiovisuais para os profissionais de saúde e alunos dos cursos técnicos, de graduação e pós-graduação em saúde.

Outro movimento para formação dos profissionais de saúde são as Residências Multiprofissionais em Saúde (RMS), com destaque para as Residências Multiprofissionais em Saúde da Família (RMSF) ofertadas por instituições de ensino ou, diretamente, por Escolas de Saúde Pública estaduais ou municipais, criando espaços de vivência da articulação ensino-serviço e de formação no cotidiano do trabalho em saúde.

Além disso, visualizam-se as propostas Programa de Apoio ao Desenvolvimento Institucional do Sistema Único de Saúde (PROADI-SUS), que tem se voltado para a formação de recursos humanos para o SUS ofertando cursos presenciais e à distância de acordo com demandas do MS.

Este passeio pelas diferentes possibilidades experimentadas para solucionar o problema da formação de trabalhadores para o SUS mostra que a equação é complexa, pois, mesmo iniciativas oficiais como a PNEPS foram ainda insuficientes para consolidar a cultura da importante e necessária atenção à formação para o SUS.

Fragilidades são apontadas para o desenvolvimento da formação de profissionais para o SUS, como: as frequentes mudanças do gestor/secretário de saúde, falta de valorização e reconhecimento dos programas educativos, a rotatividade de profissionais, alterações de coordenadores das Unidades de Saúde e a falta de recursos humanos ${ }^{2}$. Assim, a educação permanente associada aos processos de educação continuada realizadas de forma reflexiva, participativa e contínua para a formação pessoal e profissional buscam minimizar as lacunas existentes nas rotinas de trabalho e possibilitam o fortalecimento do trabalho em equipe e melhoram o cuidado prestado ao paciente e à comunidade.

É de reconhecer-se que o real sentido da formação continuada precisa ser incorporado pelos serviços para abarcar desde formações densas como as RMS até a formação a partir do cotidiano do trabalho e no trabalho, como era a premissa da PNEPS.

Ao reconhecer a importância do processo constante de aprendizado nos ambientes de trabalho, principalmente ao referir-se aos serviços de saúde, com vistas ao fortalecimento do sistema público de saúde, tem-se na educação permanente um norte, ao utilizar-se de métodos ativos para a realização das ações educativas. Contudo, incentivos financeiros e a interdisciplinaridade são indispensáveis para a efetivação dessas ações.

Essa associação tem o objetivo de sensibilizar os profissionais de saúde e gestores para mudança das suas práticas profissionais, faz-se necessário e importante que os gestores reconheçam, incentivem e façam adesão às estratégias pedagógicas para o desenvolvimento de processos educativos que possibilitem a mudança da realidade local, e isso implica em implantação e implementação de novas práticas que possibilitem a qualificação da rede de atenção à saúde, dos serviços, dos processos formativos e das práticas pedagógicas, o que permitirá adequar as necessidades e dificuldades do sistema público de saúde, na perspectiva da educação permanente para o Sistema Único de Saúde.

\section{Referências}

1. Brasil. Ministério da Saúde, Secretaria de Gestão do Trabalho e da Educação na Saúde, Departamento de Gestão da Educação na Saúde Política Nacional de Educação Permanente em Saúde: o que se tem produzido para o seu fortalecimento? Brasília: Ministério da Saúde; 2018.

2. Andrade KGM, Cortez EA, Pereira AV, Castro JA. A Implantação do Programa de Educação Permanente em Saúde num município do Noroeste Fluminense-RJ: um relato de experiência. Debates em Educação. Maceió. 2020;12(26). 